\title{
A importância da consultoria empresarial na elaboração do planejamento estratégico em empresas de pequeno porte
}

O presente trabalho tem como objetivo destacar a importância do planejamento estratégico para as empresas de pequeno porte (EPP), uma vez que elas têm representado para o Brasil, principalmente em tempos de crise, um grande potencial de crescimento social e econômico, gerando empregos e movimentando a economia. Mas devido à falta de suporte, muitas empresas têm sido fechadas, pois apesar de possuírem incentivos fiscais, apoio da prefeitura e de órgãos como o SEBRAE (Serviço Brasileiro de Apoio às Micro e Pequenas Empresas), a demanda não consegue ser atendida totalmente, devido ao grande número de empresas, tornando-se necessário a presença de consultores empresariais externos, que darão suporte às empresas em seu crescimento. Nessa perspectiva, foi realizado o estudo de caráter bibliográfico e abordagem qualitativa e quantitativa na perspectiva da consultoria empresarial e Planejamento Estratégico, crescimento. Nessa perspectiva, foi realizado o estudo de caráter bibliográfico e abordagem qualitativa e quantitativa na perspectiva da consultoria empresarial e Planejamento Estratégico,
visando o bem das empresas de pequeno porte. Tendo como fundamentação teórica os autores como, Chiavenato (2009), Oliveira (2014), Zenaro (2014), Conceição (2015) e Gomes et al. (2017). Analisando os resultados, a maioria das empresas de pequeno porte é gerenciada por um grupo familiar, no qual se torna influência direta em relação ao desenvolvimento da empresa a respeito dos valores e necessidades relacionados entre as pessoais e profissionais, causando conflitos. Nesta perspectiva, notam-se faltas de ferramentas cientificavam no gerenciamento das EPP, causando falência e desequilíbrio organizacional para empresa, apresentando, nessa assertiva, o planejamento estratégico como ferramenta de gerenciamento, com a finalidade de traçar métricas e ações a longo e curto prazo, evitando surpresas e planejando possíveis problemas futuros. Neste sentido, espera-se contribuir com esse estudo para o debate acerca da importância da consultoria empresarial na elaboraç̃o do planejamento estratégico em empresas de pequeno porte, visto a necessidade de verificar as dificuldades das pequenas empresas na elaboração e implementação do planejamento estratégico, atestando ou não que a principal dificuldade é a falta de conhecimento dos gestores sobre como utilizá-lo, o que geralmente necessita de apoio de profissionais externos.

Palavras-chave: Consultoria Empresarial; Planejamento Estratégico; Gestão.

\section{The importance of business consulting in developing strategic planning in small business} \begin{abstract}
This paper aims to highlight the importance of strategic planning for small businesses (EPP), since they have represented for Brazil, especially in times of crisis, a great potential for social and and agencies like SEBRAE (Brazilian Micro and Small Business Support Service), the demand cannot be fully met, due to the large number of companies, requiring the presence of external and agencies like SEBRAE (Brazilian Micro and Small Business Support Service), the demand cannot be fully met, due to the large number of companies, requiring the presence of external
business consultants who will support companies in their growth. From this perspective, a bibliographic study with a qualitative and quantitative approach was conducted from the perspective business consultants who will support companies in their growth. From this perspective, a bibliographic study with a qualitative and quantitative approach was conducted from the perspective
of business consulting and Strategic Planning, aiming at the good of small businesses. Having as theoretical basis the authors such as Chiavenato (2009), Oliveira (2014), Zenaro (2014), of business consulting and Strategic Planning, aiming at the good of small businesses. Having as theoretical basis the authors such as Chiavenato (2009), Oliveira (2014), Zenaro (2014),
Conceição (2015) and Gomes et al. (2017). Analyzing the results, most small businesses are managed by a family group, which becomes a direct influence on the company's development regarding the values and relo and organizational imbalance for the company, presenting, in this statement, the strategic planning as a management tool, with the purpose of tracing long and short-term metrics and actions, avoiding surprises and planning possible future problems. In this sense, this study is expected to contribute to the debate about the importance of business consulting in the preparation of strategic planning in small companies, given the ned to verify the difficulties of small companies in the preparation and implementation of strategic planning attesting or Not that the main difficulty is the lack of knowledge of managers on how to use it, which usually needs support from outside professionals.
\end{abstract}

Keywords: Business consulting; Strategic planning; Management.

Topic: Planejamento, Estratégia e Competitividade

Reviewed anonymously in the process of blind peer.
Received: 04/04/2019

Approved: 07/06/2019

Elaine Rodrigues da Mota (D)

Centro Universitário Santo Agostinho, Brasil

http://lattes.cnpq.br/8927275166397798

http://orcid.org/0000-0002-5726-2146

elaine1994rodrigues@gmail.com

Luis Fernando Silva Monteiro (iD)

Centro Universitário Santo Agostinho, Brasil

http://lattes.cnpq.br/8780743029145332

http://orcid.org/0000-0001-8764-2740

luissfernanndo@hotmail.com

Vanessa Soares do Nascimento (iD)

Centro Universitário Santo Agostinho, Brasi

http://lattes.cnpq.br/2511833678115333

http://orcid.org/0000-0002-7189-9012

vanessasoaresnascimento@gmail.com

d

DOI: 10.6008/CBPC2179-684X.2019.002.0004
Referencing this:

MOTA, E. R.; MONTEIRO, L. F. S.; NASCIMENTO, V. S.. A importância da consultoria empresarial na elaboração do planejamento estratégico em empresas de pequeno porte. Revista Brasileira de Administração Científica, v.10, n.2, p.51-63, 2019. DOI:

http://doi.org/10.6008/CBPC2179-684X.2019.002.0004 


\section{INTRODUÇÃO}

A área de consultoria empresarial vem crescendo ao longo dos anos no Brasil e no mundo, atraindo diversos profissionais, devido ao crescimento da demanda por parte das empresas que necessitam atualizarse constantemente a respeito dos métodos e técnicas de gestão empresarial. Possuir um diferencial competitivo no mercado é cada vez mais fundamental, devido à grande concorrência, provocada pela globalização. Com a instabilidade econômica e política que se tem enfrentado, muitos profissionais têm buscado a consultoria como uma saída de geração de renda extra, devido ao grande potencial de crescimento da área em meio às turbulências (OLIVEIRA, 2014).

Devido ao cenário econômico e político brasileiro, muitas empresas estão com receio de fazer novos investimentos, sendo que a consultoria poderá trazer muitos benefícios, trazendo ferramentas mais viáveis à adaptação da empresa a esse novo cenário, pois trará uma visão de um agente externo a respeito dos problemas da empresa, gerando mais conhecimento e economizando tempo com atividades operacionais. Em muitos casos, a empresa não possui ciência dos problemas existentes, ou às vezes até sabe quais problemas existem, mas não possuem habilidades e ferramentas suficientes para lidar com esses problemas, o que gera a necessidade de busca de conhecimentos externos (CROCCO et al., 2010).

Toda e qualquer empresa necessita de um planejamento estratégico que norteará o que deve ser feito de acordo com seus objetivos, permitindo, também, a identificação dos seus pontos fortes e fracos, bem como as oportunidades e ameaças existentes no mercado. Dessa forma os recursos poderão ser alocados de maneira mais eficiente e o caminho a ser traçado poderá ser mais bem definido. Mas para que o planejamento estratégico ocorra de forma adequada, é necessário a presença de profissionais qualificados, o que geralmente há deficiência em empresas de pequeno porte, necessitando de profissionais externos que os orientem na resolução de problemas (TEIXEIRA et al., 2015).

A falta do planejamento estratégico dentro das empresas de pequeno porte tem sido uma das principais causas de seu fechamento. Isso porque elas possuem uma visão míope do mercado, preocupandose apenas com a situação presente, sentem-se despreparadas para utilizar as ferramentas de planejamento, tomando atitudes errôneas com o surgimento de problemas, regredindo, em vez de agirem de forma proativa. Muitos gestores agem por meio do empirismo, deixando as ferramentas administrativas de lado, além de alegarem a falta de recursos para contratar serviços de consultoria e que as atividades operacionais ocupam um tempo excessivo dos gestores, fazendo com que tirem o foco da administração (NUNES, 2013).

A deficiência de gestores capacitados também é um dos fatores que tem prejudicado as pequenas empresas em seu crescimento e continuidade no mercado, junto à dificuldade de se obter crédito para investimentos. Mesmo que possuam linhas de crédito próprias, o acesso é dificultado por uma série de condições burocráticas, fazendo com que essas empresas tenham um acesso restrito às novas tecnologias disponíveis. Enquanto as grandes empresas possuem maiores vantagens materiais e financeiras, as pequenas empresas possuem vantagens quanto a sua flexibilidade e adaptação, incentivando à inovação (ROVERE, 2001). 
Através do planejamento estratégico, as organizações podem dirigir seus esforços para o alcance dos objetivos de forma eficiente, eficaz e efetiva, evitando, assim possíveis falhas, principalmente para as empresas de pequeno porte que sofrem maior impacto com as mudanças do mercado. Conhecer os problemas da empresa profundamente, o que deve ser mantido e modificado, bem como o mercado em que está inserida, dará maior segurança quando se enfrentar problemas, facilitando a tomada de decisões. Ainda assim, muitos gestores ainda não veem o planejamento como algo essencial para a manutenção e/ou crescimento organizacional (MARQUES et al., 2016).

As pequenas empresas possuem grande representatividade na economia mundial, sendo um dos principais geradores de emprego e renda. Além de possuírem uma grande capacidade de inovação, mas que muitas vezes é limitada pela falta de recursos financeiros e tecnológicos, o que acaba inibindo seu crescimento, sendo que a tecnologia tem se tornado cada vez mais indispensável para o crescimento e manutenção das empresas, tanto para o relacionamento com os clientes e demais parceiros, como para a execução de atividades operacionais e gerenciais.

Mas para que o planejamento estratégico seja elaborado e executado de forma adequada é indispensável a presença de profissionais capacitados que auxiliem a empresa a elaborá-lo e colocá-lo em prática, trazendo uma maior objetividade e imparcialidade ao processo. Desta forma, questiona-se: qual a importância da consultoria empresarial na elaboração do planejamento estratégico em empresas de pequeno porte?.

\section{METODOLOGIA}

O estilo de metodologia utilizada para o presente artigo teve por base a pesquisa descritiva, pois tem como objetivo observar os fenômenos estudados. No caso desta pesquisa, pretende-se observar os fatores que dificultam a implementação do planejamento estratégico dentro das empresas de pequeno porte, e se o principal fator é a falta de conhecimento por parte dos gestores organizacionais, de forma que esses fatores sejam descritos, classificados e interpretados. Esse tipo de pesquisa caracteriza o fato estudado, mas não explica o 'porquê' das coisas, deixando essa tarefa para outros tipos de pesquisa (VIEIRA, 2017).

Quanto aos meios, a pesquisa se caracteriza como estudo de problemas identificado no mercado de forma literária. O estudo tem como objetivo solucionar problemas onde não se sabe o porquê ou como de algum fato, desta forma busca-se soluções para estes problemas, além de ser uma ferramenta eficiente quando o pesquisador não tem domínio sobre o problema em questão, fazendo com que ele se aprofunde ao máximo sobre o problema buscando resolvê-lo ou deixar questionamentos para pesquisas futuras (MAFFEZZOLLI et al., 2016).

\section{DISCUSSÃO TEÓRICA}

A consultoria empresarial é um processo onde profissionais externos atuam dentro das organizações com o objetivo de identificar problemas e propor formas de saná-los, sem interferências diretas, apenas orientando os funcionários da empresa a melhor forma de agir, cabendo à empresa o processo de tomada 
de decisões. Para que o processo de consultoria seja consolidado de maneira correta, é necessário que exista um contrato de prestação de serviços onde esteja claro o papel de ambas as partes. É importante também que o executivo da empresa esteja envolvido ativamente em todo o processo e que o consultor empresarial apresente postura ética na prestação do serviço (OLIVEIRA, 2014).

A Consultoria é o ato de um cliente fornecer, dar e solicitar, pedir pareceres, opiniões, estudos, a um especialista contratado para que este auxílio apoie, oriente o trabalho administrativo, pode-se dizer que a consultoria é uma troca onde o cliente fornece informações da empresa e cabe ao consultor diagnosticar o problema e orientar da melhor forma possível.

A consultoria não é algo recente, desde os primórdios dos tempos, os reis, imperadores e monarcas pediam orientações de sábios/filósofos. Atualmente, o Brasil é considerado um dos países que mais cresce na área de atuação das consultorias, devido a essa ser considerada um dos métodos de solução de problemas capaz de gerenciar mais rapidamente as mudanças ocorridas, deixando de lado o conhecimento empírico para basear-se em ferramentas práticas e técnicas administrativas. É preciso observar as particularidades de cada empresa, para que sejam aplicados serviços de acordo com os problemas diagnosticados. Pacotes prontos podem não ser suficientes, embora uma ferramenta possa solucionar problemas diferentes (CONCEIÇÃO, 2015).

A consultoria também pode dar suporte no desenvolvimento dos funcionários, principalmente dos gestores que precisam desenvolver competências organizacionais: sociais, de negócio e técnicas. Essas competências devem ser alinhadas a empresa e seus objetivos. Nas pequenas empresas, observa-se a falta principalmente de competências administrativas, por serem na maioria das vezes familiares, os proprietários, gestores, não possuem uma formação adequada para gerir o negócio. Problemas de comunicação e relacionamentos com clientes, funcionários e fornecedores também são constantes (CASSOL et al., 2016).

Ao contrário do que muitos pensam, os momentos de crise são muito favoráveis à criação de oportunidades. E muitos empreendedores veem na consultoria um grande mercado a ser explorado, sendo um dos setores com maior presença de empreendedores. A consultoria traz aos profissionais, maior flexibilidade e renda extra, em situações em que se encontram desempregados ou impossibilitados de exercer suas atividades. Os consultores estabelecem seus próprios horários, com um prazo para conclusão das melhorias, apresentando resultados. Mas, para vender seus serviços, é necessário que o profissional seja bem capacitado e que seja especializado na área em que o cliente necessita, além de atualização de conhecimento constante (DEGEN, 2009).

A consultoria também pode dar suporte no desenvolvimento dos funcionários, principalmente dos gestores que precisam desenvolver competências organizacionais: sociais, de negócio e técnicas. Essas competências devem ser alinhadas a empresa e seus objetivos. Nas pequenas empresas, observa-se a falta principalmente de competências administrativas, por serem na maioria das vezes familiares, os proprietários, gestores, não possuem uma formação adequada para gerir o negócio. Problemas de comunicação e relacionamentos com clientes, funcionários e fornecedores também são constantes (CASSOL et al., 2016).

Ao definir sua visão a empresa projetará uma imagem do futuro onde quer estar e com isso cria um elo motivador entre os membros da organização, além de uma imagem com maior credibilidade para seus 
clientes, fornecedores e demais empresas, pois ela buscará ser referência baseada nos objetivos definidos. A missão dirá aos clientes de que forma quer atingi-los e os benefícios que ele adquirirá ao comprar seus produtos e/ou serviços, permitindo a visualização do público a ser atendido. Para que sejam executadas de forma correta, é importante estabelecer políticas que colocaram regras de como tudo deve ser feito e, por fim, devem ser disseminados entre seus stakeholders (CARAVANTES et al., 2005).

É importante que, antes do processo de negociação, o consultor busque se planejar, buscando informações sobre a empresa. Para que haja uma relação de parceria, é necessário que se estabeleça uma relação de ganha-ganha, sendo que as duas partes, consultor e cliente, atinjam seus objetivos. Deve-se buscar conhecer a linguagem do interlocutor, para que o cliente entenda as documentações utilizadas e os benefícios que a consultoria trará, deixando a comunicação o mais clara possível (ZENARO, 2014).

É essencial para qualquer ser humano conhecer-se a si mesmo para conseguir desenvolver-se, tanto pessoalmente, quanto profissionalmente. Saber suas forças e fraquezas, seu propósito de vida, a que lugar pertence, fará com que se possa trabalhar em busca do aperfeiçoamento de suas forças. Ao ser especialista em uma determinada área, muitos profissionais acabam limitando sua visão apenas ao que conhecem, desprezando outras áreas que trariam benefícios a sua vida. Conhecendo-se, o profissional poderá alocar seus esforços no desenvolvimento das suas melhores competências, delegando aquelas em que é ineficiente (DRUCKER, 1999).

Os consultores podem ser comparados a médicos organizacionais, pois buscam o tratamento para os problemas da empresa. Mas assim como os médicos muitas vezes tratam seus pacientes de forma distante, muitos consultores também são 'frios', quanto aos problemas da empresa, justificando dar maior objetividade ao trabalho, o que gera muitas críticas a profissão de consultor, além do fato de muitos ainda verem a consultoria como modismo ou mesmo a solução para todos os problemas da empresa (ANUNCIATTO, 1999).

Pesquisas sobre consultoria e sua interferência no meio organizacional ainda são escassas no Brasil, o que torna necessário maior estudo sobre essa área que tem sido cada vez mais fundamental para o desenvolvimento das empresas. As empresas buscam os serviços de consultoria quando querem adquirir informações sobre algo ou quando não tem tempo para executar tal atividade. Algumas empresas buscam a consultoria para identificar os problemas existentes e a forma de tratá-los. A consultoria também pode trabalhar com atividades que estimulem o cliente a descobrir suas próprias falhas e consequentemente a melhor solução para isso, envolvendo o cliente no processo de tomada de decisões (CORREIA et al., 2010).

Quanto à formação do consultor, diz-se que a Administração é uma das áreas mais qualificadas para o cargo, devido ao vasto conhecimento sobre as organizações, desde atividades simples às mais complexas, podendo o profissional de administração atuar em várias áreas, tanto como gestor, quanto em áreas específicas, como finanças, marketing, recursos humanos. Além do que as funções da Administração planejar, organizar, dirigir, controlar, estão intimamente ligadas às atividades executadas pelos consultores empresariais. Possuem conhecimentos sobre organizações tanto teóricos, como práticos (BELFORT, 2004). 
Embora a flexibilidade, maior autonomia, possibilidade de crescimento e desenvolvimento profissional tragam satisfação aos consultores, existem também pontos negativos em ser consultor que devem ser observados, como, a instabilidade financeira e a insegurança da carreira. Mas observa-se maior satisfação entre os profissionais do que insatisfação. Por serem profissionais externos muitas vezes os profissionais também não têm um reconhecimento de seu trabalho satisfatório. O feedback por parte dos dirigentes da organização é essencial para que tanto o consultor quanto a empresa vejam as melhorias proporcionados (MORAES et al., 2010).

Um dos maiores desafios organizacionais é alinhar os interesses dos funcionários aos objetivos da empresa, pois cada nível tem uma interpretação diferente de tais objetivos e, claro, geralmente alinham isso aos seus interesses pessoais. Os ruídos na comunicação também dificultam o alinhamento desses interesses, quanto maior a organização, maior a dificuldade de todos terem informações precisas, o que as pequenas empresas deveriam ter como vantagem por estarem mais próximas de seus funcionários, clientes e fornecedores. Mas ainda a uma grande dificuldade por parte dessas empresas de efetuarem mudanças, o que é fundamental na elaboração de qualquer processo de planejamento. Não há planejamento sem mudanças (KWASNICKA, 1995).

Devido à grande importância socioeconômica para o país, torna-se essencial a busca de respostas de quais fatores interferem positiva e negativamente sobre essas empresas, de forma que sejam criadas medidas para diminuir o máximo possível os fatores que fazem com que elas sejam extintas precipitadamente, garantindo assim sua sobrevivência em tempos de crise. Cabe aos consultores empresariais demonstrar a esses gestores o qual significativo é aliar suas experiências práticas ao conhecimento teórico e os retornos trazidos com a adoção de tais medidas (RODRIGUES et al., 2013).

Os consultores empresariais são diretamente responsáveis pelos resultados apresentados pelos clientes, seja de sucesso ou fracasso, devendo oferecer pacotes customizados de acordo com as necessidades do cliente. Por serem agentes externos possuem uma visão mais ampla dos problemas e podem oferecer soluções mais objetivas em um espaço menor de tempo, podendo as consultorias ser especializadas, quando possuem foco em poucos assuntos de determinada área, consultoria total que abrange diversos problemas que podem estar presentes nas organizações, cooperativa de consultores, quando consultores com especialidades diferentes se unem e a consultoria globalizada que pode atuar em diferentes países (SANTOS et al., 2011).

\section{Planejamento estratégico}

O planejamento estratégico é o processo pelo qual são feitas estratégias em longo prazo, para inserir a empresa no mercado em que ela atua, propagando sua missão. Tem como objetivo buscar constantemente métodos para o alcance dos objetivos, buscando uma previsão do futuro, medindo os riscos e reavaliando as estratégias sempre que necessário. Ele abrange toda a organização, e é estabelecido pela cúpula organizacional, onde todos os membros terão que trabalhar em comum acordo para que o processo ocorra de forma estruturada (CHIAVENATO et al., 2009). Oliveira (2009), diz que 
O planejamento estratégico em sua elaboração possui três dimensões operacionais: o delineamento, a elaboração e a implementação. O delineamento compreende a estrutura metodológica do processo, bem como o profissional que irá auxiliar na elaboração, podendo ser um consultor ou um executivo da empresa. A elaboração fica com a obrigação de identificar as oportunidades e as ameaças do ambiente, avaliar os pontos fortes e fracos e sua capacidade de retirar vantagens das oportunidades, explicitar os objetivos e as metas a serem alcançadas e também desenvolver maneiras para realização das estratégias. Enquanto a implementação envolverá os assuntos organizacionais, o sistema de informação, orçamentário, sistemas de incentivos, o treinamento e liderança necessária para desenvolver o processo e colocá-lo em prática.

Nessa perspectiva, a metodologia do planejamento estratégico é plasmada de acordo com as necessidades e o nível da aplicação, ou seja, ele é uma ferramenta flexível, no qual apresenta técnicas e modelo de aplicação adaptável a diversos cenários da empresa, sendo ele essencial na tomada de decisão dos gestores e situações de crises. O planejamento estratégico tem a visão da organização com o um todo, princípio da teoria sistêmica, analisando o cenário interno e externo, os pontos positivos e negativos com a finalidade de traçar metas e ações a longo prazo.

A empresa deve primeiramente definir sua visão (onde ela pretende estar no futuro), depois a definição dos valores (que permitiram a identificação dos stakeholders com a organização) e por último a missão (que deve estar de acordo com a visão e os valores). A falta destas ferramentas pode gerar problemas no planejamento estratégico. A verificação das forças, fraquezas, oportunidades e ameaças realizada através da análise SWOT (Stregths, Weknesses, Opportunities, Threats) também é de fundamental importância para conhecer melhor a empresa e de que forma ela é percebida pelo mercado (RIBEIRO et al., 2016).

Através da missão, a empresa saberá que tipo de público pretende alcançar e qual o seu propósito dentro da sociedade, sendo ainda mutável ao longo do tempo de acordo com o ambiente em que estão inseridas no momento. É preciso que sejam analisadas as oportunidades e ameaças principalmente relacionadas ao ramo de negócios, mudanças tecnológicas, ação e controle do governo e conjuntura econômica e sociedade (MAXIMIANO, 2004).

Muitos empresários geralmente colocam a culpa do fechamento de suas empresas a fatores externos, como o governo, tributação, etc.. Mas o que acontece é que essas empresas na maior parte das vezes são abertas sem nenhum planejamento prévio. Principalmente para as pequenas empresas essa ferramenta é de grande importância, pois auxiliará os gestores com a melhor utilização dos recursos escassos e evitar atividades desnecessárias. Primeiramente, devem-se buscar informações sobre o ambiente em que está inserida, para só depois traçar os objetivos e planos de ação, é imprescindível também que toda equipe esteja integrada. Deve-se realizar o diagnóstico estratégico, análise interna e externa, bem como verificar as oportunidades e ameaças existentes (FERREIRA, 2006).

Um dos principais empecilhos da aplicação do planejamento estratégico pelas empresas de pequeno porte é que seus gestores preocupam-se mais com problemas em curto prazo e se esquecem dos problemas que poderão afetar a organização no futuro. Aos poucos, os gestores têm criado interesse em planejar-se devido à necessidade de adaptação ao cenário atual. O planejamento estratégico permitirá uma visão sistêmica da empresa, desde problemas gerenciais a problemas operacionais, podendo ser levantados 
através da matriz GUT todos os problemas da empresa, onde devem ser atacados primeiramente os problemas com maior gravidade, urgência e tendência (MONTEIRO et al., 2011).

No processo de planejamento estratégico é necessário que sejam estabelecidos objetivos e estratégias para o alcance desses objetivos. $\mathrm{O}$ objetivo deve ser concreto e numérico, com valores e prazos estabelecidos. Deve-se também verificar a viabilidade das estratégias através da elaboração de demonstrativos financeiros, permitindo assim que a empresa verifique se possui recursos suficientes disponíveis, como por exemplo, treinamento de funcionários, mudanças no layout, aquisição de novas máquinas, equipamentos e tecnologias, entre outras despesas geradas (ALMEIDA, 2010).

O planejamento estratégico é um processo sistemático que envolve toda a organização, permite uma visão geral da empresa e tem como foco o futuro da organização, traçando estratégias para aquilo que a organização quer ser em longo prazo. Traz também a criação de valor para a empresa, tanto fornecedores, clientes, quanto funcionários, pois dá maior solidez à empresa como um todo. Nesse processo destaca-se a necessidade de engajar todos os membros na implementação, pois é fundamental que todo o processo esteja alinhado, sempre observando sua continuidade e que não fique apenas no papel, mas que seja executado por todos os envolvidos, observando por fim o monitoramento e devidas ações corretivas (CHIAVENATO, 2009).

Devido à grande imprevisibilidade enfrentada cada vez mais no mundo dos negócios, tem-se questionado quanto a sua eficácia, também pode ser considerado por muitos como algo que gere resistência a mudanças, principalmente em empresas de pequeno porte. O planejamento estratégico deve ser escrito, devendo conter os objetivos e estratégias assim como métodos de controle, ser realizado em longo prazo, contendo plano de controle e o passo a passo para se atingir os objetivos com os seus devidos responsáveis, cabendo aos gestores da alta cúpula verificar a adequação de tais ações aos objetivos (OLIVEIRA et al., 2010).

Com um planejamento estratégico bem definido e alinhado, será possível estabelecer o posicionamento estratégico da empresa. Onde atenderá melhor às necessidades de seus clientes, o que a destacará das demais empresas, unindo posicionamento de mercado (definição do setor em que a empresa atuará) e posicionamento psicológico (que trabalhará com a mente dos consumidores com o objetivo de influenciá-los na decisão de compra) (MARTINS, 2017).

\section{Pequenas empresas no Brasil}

O surgimento das pequenas empresas no Brasil deu-se da necessidade de Portugal de criar uma estrutura produtiva local, com o objetivo de atrair principalmente empreendedores para a manutenção da nova colônia e para cobrir gastos de frete e defesa da nação, através de pagamento de impostos. Mesmo que o objetivo principal da época fosse a exploração dos recursos para exportação, era preciso que o território fosse ocupado para evitar que outros povos invadissem as novas terras. Supõe-se que as atividades das pequenas empresas tenham se iniciado no setor agrícola com a produção de açúcar, que era o principal produto do período colonial e era considerada especiaria de luxo, utilizada apenas por nobres (SOUZA et al., 2007). 
Atualmente, as microempresas são aquelas que possuem renda bruta anual igual ou inferior a $\mathrm{R} \$ 360.000,00$ (trezentos e sessenta mil reais), e as pequenas empresas são aquelas que possuem receita bruta anual superior a $\mathrm{R} \$ 360.000,000$ (trezentos e sessenta mil reais) e igual ou inferior a $\mathrm{R} \$ 4.800 .000,00$ (quatro milhões e oitocentos mil reais) (BRASIL, 2006), sendo que as pequenas empresas do setor Industrial podem ter de 20 a 99 funcionários e as empresas do setor de Comércio e Serviços podem ter de 10 a 49 funcionários (GOMES et al., 2017).

Quadro 1: Classificação das MPEs segundo o número de faturamento.

\begin{tabular}{|c|c|c|}
\hline PORTE & SETOR & RECEITA BRUTA ANUAL IGUAL OU INFERIOR \\
\hline \multirow{2}{*}{ Microempresa } & Comércio e Serviço & \multirow{2}{*}{$\mathrm{R} \$ 360.000,00$} \\
\hline & Indústria & \\
\hline \multirow{2}{*}{ Pequenas Empresas } & Comércio e Serviço & \multirow{2}{*}{$\begin{array}{c}R \$ 360.000,00 \text { e igual ou inferior é } R \$ \\
3.600 .000,00\end{array}$} \\
\hline & Indústria & \\
\hline
\end{tabular}

As microempresas e empresas de pequeno porte pagam uma taxa única, calculada em cima do seu faturamento, através do Simples Nacional, que é um regime tributário próprio para estas empresas, onde estão inclusos tributos como ICMS, IR, PIS IPI e ISS. Embora não necessitem ter escrituração mercantil, devem possuir escrituração contábil, além de emitirem nota fiscal e arquivar quaisquer documentos relacionados ao exercício de suas atividades, se a empresa for optante do Simples Nacional, caso contrário não será dispensado (COELHO, 2012).

Em relação ao Simples Nacional, atualmente, existem cadastradas na base de 12 milhões de empresas, gerando mais da metade de emprego no Brasil atualmente (54,5\%), tendo grande atuação na economia brasileira, em que maioria das empresas formais (98,5\%), participam com 27\% do PIB. E para 2019, de acordo com análise feita pelo Sebrae a partir de dados da Receita Federal, a expectativa é de que sejam constituídas até 1,5mi de novas empresas, levando em consideração os microempreendedores individuais, as microempresas e as empresas de pequeno porte.

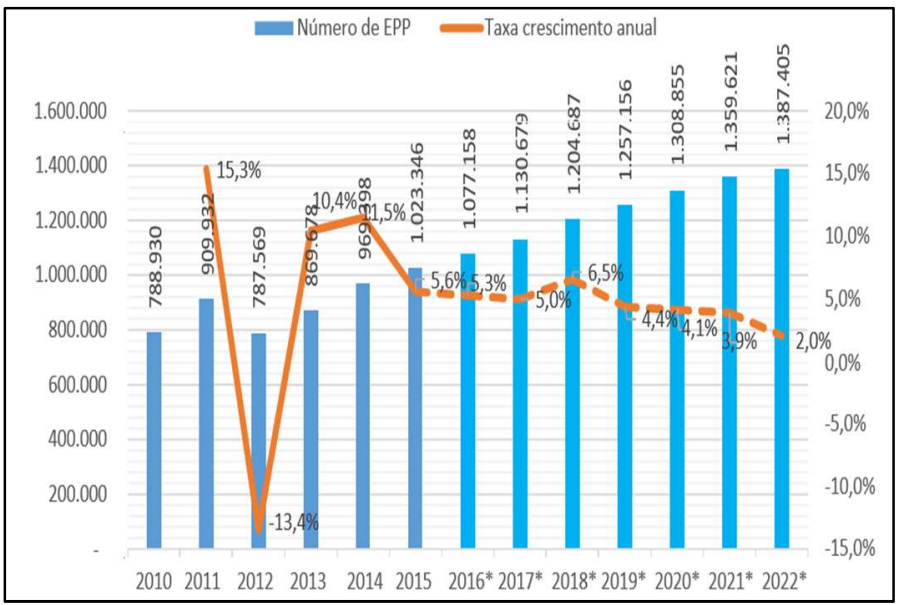

Figura 1: Evolução da quantidade de EPP (2010 a 2022). Legenda: * Projeções.

Aproximadamente $98,5 \%$ das empresas brasileiras são consideradas micro e pequenas empresas e são responsáveis por grande parte da geração de empregos do país, segundo a pesquisa de mercado Realizado pelo SEBRAE em 2018. A globalização tem feito com que as pequenas empresas ocupem espaços 
antes ocupados apenas por grandes empresas, pois através da internet torna-se mais prático o contato com o cliente, fornecedores e demais participantes do mercado. As atividades antes executadas em grandes empresas estão sendo dissociadas em nichos de mercados agora ocupados pelas pequenas empresas (TACHIZAWA et al., 2007).

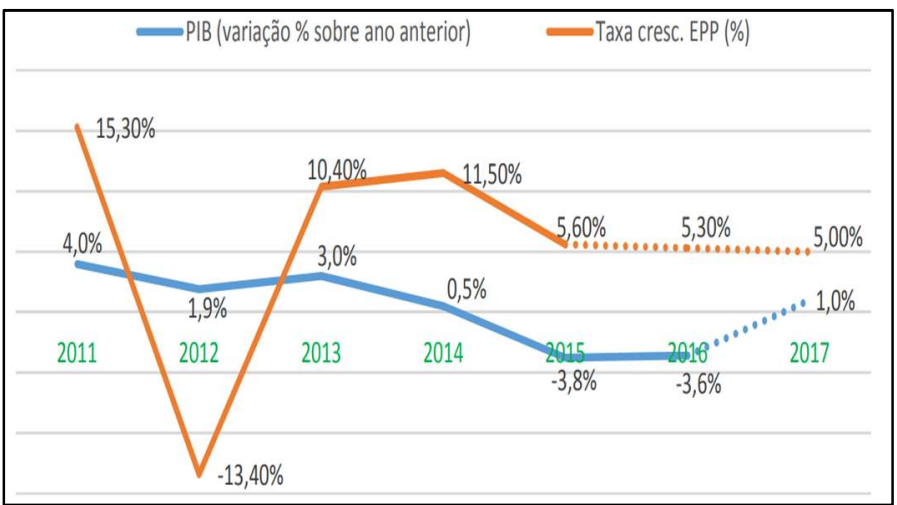

Figura 2: Taxa de crescimento das EPP X Variação do PIB.

Essas empresas enfrentam diversos problemas para sobreviver em meio ao mercado competitivo em que estão inseridas, pois apesar de possuírem grande taxa de natalidade, também possuem grandes taxas de mortalidade, muitas delas encerrando suas atividades antes mesmo de dois anos de existência; isso porque não possuem ferramentas de gestão e incentivos fiscais adequados. Além de terem acesso dificultado a Instituições Financeiras devido às exigências que devem ser cumpridas para que sejam concedidos empréstimos, o que dificulta também o acesso à inovação tecnológica e demais investimentos (RODRIGUES et al., 2013).

A maior parte das empresas familiares é de pequeno porte ou médio porte. Essa influência faz com que o processo decisório seja centralizado nos membros da família, em especial no patriarca, interferindo até mesmo em seu crescimento, pois só veem a necessidade de crescimento até o ponto de satisfazer as necessidades da família, e não pensando no que é melhor para a empresa. Essa interferência familiar gera grandes disfunções gerenciais, além de não haver separação entre o capital da empresa e os gastos familiares, apesar de a empresa interferir de certa forma na vida dos membros do "clã familiar", como na escolha de suas profissões, formação acadêmica e até mesmo nos casamentos (ROCHA, 2000).

As empresas familiares costumam prezar pela confiabilidade em seus funcionários: quanto mais antigos são os profissionais dentro da empresa, mais satisfeitos são com a empresa. Embora muitos sejam os conflitos internos, que por mais que sejam considerados mais fáceis de se resolver, acabam não sendo pela dificuldade de se separar os problemas familiares dos problemas organizacionais. Observa-se também que entre os jovens, a lealdade a empresa não é tão significativa quanto aos colaboradores mais antigos, ou seja, caso tenham oportunidades melhores trocariam de empresa (CARMO et al., 2017).

Ainda há muita resistência por parte das pequenas empresas da implementação de ferramentas de gestão, como o planejamento estratégico, pois por viverem em um eterno "apaga incêndio", acreditam não ter tempo para executar atividades de planejamento por terem a visão equivocada de que esse tipo de ferramenta é apenas algo técnico e que não funciona na prática, o que apenas desperdiçaria tempo. Acontece 
que o processo de planejamento deve ser contínuo, planejando, desenvolvendo, controlando e avaliando (método PDCA) (COELHO et al., 1999).

Com o cenário competitivo vivenciado atualmente, é de suma importância para toda e qualquer empresa, não só de grande porte, mas principalmente para as empresas de pequeno porte, possuírem um planejamento estratégico adequado. Por geralmente essas empresas serem familiares, há uma dificuldade na elaboração desta ferramenta por falta de conhecimentos dos gestores ou por muitas vezes os mesmos estarem envolvidos em atividades operacionais, deixando o nível estratégico a desejar. Essas empresas também possuem grande dificuldade em incentivos financeiros.

Muitas empresas têm sido fechadas devido à falta de planejamento, possuindo uma grande taxa de mortalidade das pequenas empresas, o que tem gerado também receio em fazer novos investimentos financeiros, principalmente com capacitação dos funcionários. A elaboração do planejamento estratégico dirá onde a empresa está e aonde ela quer chegar, destacando os pontos fortes e fracos, bem como as oportunidades e ameaças existentes, norteando-a ao alcance desses objetivos por meio do plano de ação e indicadores de desempenho, fazendo com que a empresa possa antecipar-se aos problemas.

Outro problema que tem gerado a inibição do crescimento dessas empresas é devido aos donos delas ainda as verem apenas como um meio de subsistência para suas famílias e não como algo importante para a sociedade e economia. O envolvimento demasiado dos familiares dentro da organização também dificulta o processo de tomada de decisões, trazendo decisões subjetivas, ou até mesmo inibindo ações importantes dos gestores por receio de causar conflitos internos. As contratações geralmente são baseadas pela confiança no contratado e não pelo seu potencial de conhecimento.

A inovação é um dos principais diferenciais e fator de manutenção das pequenas empresas no mercado. Saber gerenciar o conhecimento é de fundamental importância, como também saber gerenciar os demais recursos existentes na organização, de forma a utilizá-los o mais eficiente possível, evitando gastos e desperdícios, buscando criar produtos e soluções diferenciadas dos concorrentes. Assim, quanto mais contato a empresa tiver com o conhecimento externo mais a empresa absorverá informações, seja pelo contato com outras empresas, através de benchmarking ou pelo processo de consultoria empresarial (LEITE et al., 2016).

\section{CONCLUSÕES}

O estudo identificou que as EPP (Empresas de Pequeno Porte), no Brasil, representam maior parte de organizações empresariais atualmente, sendo o maior gerador de empregos e tento forte atuante na movimentação da economia brasileira. Sendo ela uma forma de empreender que surgiram desde os primórdios das atividades econômicas realizados pela sociedade que aos anos vem se atualizado de acordo com as necessidades do mercado global.

As pequenas empresas, sendo elas de fácil constituição, em que consequentemente encontram desafios em manter atividades no mercado, visto que os empreendedores não têm conhecimento técnico necessário para manter atividade empresarial sustentável, causando déficits no mercado, sendo necessário 
que eles adquirirem desde o ato de constituição, gerenciamento e falência habilidades e conhecimentos necessários para redução de risco.

E como ferramenta de gerenciamento e tomada de decisão, o planejamento estratégico, processo contínuo nas organizações para a mapeamento do cenário atual e as perspectivas para o futuro, visando a redução de risco e crescimento da empresa. O planejamento estratégico, que consiste na matriz de SWOT que permite a análise do ambiente interno e externo da organização, sendo ferramenta competitiva e fundamental para qualquer empresa que deseja crescer no mercado e torna-se sustentável.

Notando-se que existem empreendedores que atuam no conhecimento empírico, ou que não precisam de informações e preparo, e com isso ocorrem as maiores dificuldades devido à falta de conhecimento, é fundamental que o empresário esteja munido de ferramentas e conhecimento técnico para que atuem de forma eficiente na organização empresarial.

Portanto, conclui-se que as empresas de pequeno porte para se tornar eficaz e competitiva é necessário que o processo de mudança seja algo contínuo. A empresa necessita ser flexível com as mudanças e adapta-se a ela. O gestor nesse processo é ser fundamental, pois é necessário que tenha uma visão holística de todo o processo da empresa, conhecimento técnico, percepção do futuro para tomada de decisões e uma personalidade empresarial mutável, em virtude de as empresas atualmente encontrarem-se em um cenário de altas atualizações e revoluções.

\section{REFERÊNCIAS}

ALMEIDA, M. I. R.. Manual de Planejamento estratégico: desenvolvimento de um plano estratégico com a utilização de planilhas Excel. 3 ed. São Paulo: Atlas, 2010.

ANUNCIATTO, R.. Um gostinho do próprio remédio: até que ponto empresas de consultoria no Brasil adotam em si mesmas aquilo que prescrevem a seus clientes?. Revista de Administração de Empresas, v.39, n.4, p.2-12, 1999.

BRASIL. Lei Complementar n.123 de 14 de dezembro de 2006. Lei Geral das Micro e Pequenas empresas. Brasília: DOU, 2006.

CAMPOS, V. F.. Gerenciamento da rotina do trabalho do dia a dia. 9 ed. Belo Horizonte: Falconi, 2013.

CARMO, L. J. O.; KENDLER, V.; MURTA, R. S.. O Desafio da Geração Y em Processos de Sucessão Familiar nas Empresas. Revista da Micro e Pequena Empresa, v.11, n.2, p.119-133, 2017.

CHIAVENATO, I.; SAPIRO, A.. Planejamento Estratégico: fundamentos e aplicações. 2 ed. Rio de Janeiro: Elsevier, 2009.

COELHO, F. U.. Manual de direito comercial: direito de empresa. 24 ed. São Paulo: Revistas dos Tribunais, 2012

COELHO, J. M; SOUZA, M. C. A. F.. A importância do planejamento estratégico para empresas de pequeno porte. In: CONGRESSO BRASILEIRO DE CUSTOS. Anais. São Paulo: 1999.
CONCEIÇÃO, G. J.. Consultoria empresarial como ferramenta de gestão financeira para pequenas empresas: um estudo de caso na FKS Moda Center da cidade de Conceição do Almeida-BA. Formadores, v.8, n.2, p.25, 2015.

CORREIA, F. B. C.; FEITOSA, M. G. G.; VIEIRA, N. S.. A consultoria como oportunidade de aprendizagem para as Organizações Não Governamentais: um estudo na cidade de Recife/PE. Revista de Administração da UFSM, v.3, n.2, p.245-259, 2010.

CROCCO, L.; GUTTMANN, E.. Consultoria empresarial. 2 ed. São Paulo: Saraiva, 2010.

DEGEN, R. J.. O empreendedor: empreender como opção de carreira. São Paulo: Pearson Prentice Hall, 2009.

FERREIRA, M. A. D.. A importância do planejamento estratégico para o crescimento das empresas. Maringá Management, v.2, n.1, 2006.

GOMES, O. J.; OLIVEIRA, U. G.; SILVA, P. Z. P.. Uma análise das Informações Contábeis utilizadas pelos Micro e Pequenos Empreendedores do Município de Jacaraú/PB para o processo de Tomada de Decisões. Revista da Micro e Pequena Empresa, v.11, n.2, p.18-32, 2017.

KWASNICKA, E. L.. Introdução à Administração. 5 ed. São Paulo: Atlas, 1995.

LEITE, G. A. F.; COLARES, A. F. V.. Relação entre competências empreendedoras e a taxa de crescimento de 
vendas de Pequenas e Médias Empresas brasileiras. ReGePe, v.5, n.1, p.117-140, 2016.

MAFFEZZOLLI, E. C. F.; BOEHS, C. G. E.. Uma reflexão sobre o estudo de caso como método de pesquisa. Revista da FAE, v.11, n.1, 2016.

MARTINS, P. R.. O impacto do posicionamento estratégico no volume de produtos comercializados por uma empresa de pequeno porte do ramo calçadista do Vale dos Sinos/RS. Revista da Micro e Pequena Empresa, v.11, n.2, p.89-104, 2017.

MAXIMIANO, A. C. A.. Fundamentos de Administração: manual compacto para cursos de formação tecnológica e sequenciais. São Paulo: Atlas, 2004

MONTEIRO, J. M.; BARBOSA, J. D.. Controladoria empresarial: gestão econômica para as micro e pequenas empresas. Revista da Micro e Pequena Empresa, v.5, n.2, p.38-59, 2011.

MORAES, L. F. R.; SICOLI, C. R.. Qualidade de vida e fontes de pressão no trabalho do consultor organizacional em Belo Horizonte. Revista Gestão \& Tecnologia, v.3, n.1, 2010.

NUNES, J. A.. A utilização do planejamento estratégico como ferramenta de gestão na pequena empresa. Revista da Micro e pequena Empresa, v.7, n.2, 2013.

OLIVEIRA, D. P. R.. Manual de consultoria empresarial: conceitos, metodologia, práticas. 12 ed. São Paulo: Atlas, 2014.

OLIVEIRA, D. P. R.. Planejamento estratégico: conceitos, metodologia e práticas. 23 ed. São Paulo: Atlas, 2007.

OLIVEIRA, J.; TERENCE, A. C. F.; ESCRIVÃO, E. F.. Planejamento estratégico e operacional na pequena empresa: impactos da formalização no desempenho e diferenças setoriais. Gestão Organizacional, v.3, n.1, p.119, 2010.

PARREIRA, F. E.. Consultoria, consultores e clientes. São Paulo: Érica, 1997.

RIBEIRO, C. C.; TAVARES, M. C.. Planejamento estratégico: fatores dificultadores e facilitadores em sua implementação em uma indústria de médio porte de MG. Revista de Administração \& Ciências Contábeis, v.10, n.1, 2016.
ROCHA, A.. Empresas e clientes: um ensaio sobre valores e relacionamentos no Brasil. São Paulo: Atlas, 2000.

RODRIGUES, J. L. K.; SANTOS, O. F.. Planejamento Estratégico Situacional e suas Contribuições: Um Novo Paradigma Para a Gestão de Micro e Pequenas Empresas. Economia \& Gestão, v.16, n.44, p.109-141, 2016

RODRIGUES, T. K. A.; BOAS, A. A. V.. Ferramentas de gestão nas microempresas brasileiras. Jundiaí: Paco, 2013.

ROVERE, R. L.. Perspectivas das micro, pequenas e médias empresas no Brasil. Revista de Economia Contemporânea, v.34, p.137-154, 2001

SANTOS, J. A. C. C.. Consultoria organizacional: utilização do marketing de relacionamento pelas pequenas empresas de consultoria e pelos consultores autônomos na busca de competitividade. Revista da Micro e Pequena Empresa, v.5, n.3, p.21-39, 2011.

SILVA, A. H.; FOSSÁ, M. I. T.. Análise de conteúdo: exemplo de aplicação da técnica para análise de dados qualitativos. Dados em Big Data, v.1, n.1, p.23-42, 2017.

SILVA, L. V. B.. Características Qualitativas da Pesquisa Científica: Uma visão para pesquisas qualitativas e quantitativas. Id On Line Revista de Psicologia, v.11, n.35, p.607-614, 2017.

SOUZA, J. H.; MACHADO, L. C.; OLIVEIRA, C. A. S.. As origens da pequena empresa no Brasil. Revista da Micro e Pequena Empresa, v.1, n.1, p.54-65, 2007.

TACHIZAWA, T.; POZO, H.. Gestão de recursos humanos em micro e pequenas empresas: um enfoque de gestão ambiental e responsabilidade social para seu crescimento. Revista da Micro e Pequena Empresa, v.1, n.1, p.4-23, 2007.

TEIXEIRA, C. A. C.; DANTAS, G. G. T.; BARRETO, C. A.. A Importância do Planejamento Estratégico para as Pequenas Empresas. Revista Eletrônica Científica da FAESB Ano, v.2, n.1, 2015.

VIEIRA, V. A.. As tipologias, variações e características da pesquisa de marketing. Revista da FAE, v.5, n.1, 2017.

ZENARO, M.. Técnicas de Negociação: como melhorar seu desempenho pessoal e profissional nos negócios. São Paulo: Atlas, 2014.

A CBPC - Companhia Brasileira de Produção Científica (CNPJ: 11.221.422/0001-03) detém os direitos materiais desta publicação. Os direitos referem-se à publicação do trabalho em qualquer parte do mundo, incluindo os direitos às renovações, expansões e disseminações da contribuição, bem como outros direitos subsidiários. Todos os trabalhos publicados eletronicamente poderão posteriormente ser publicados em coletâneas impressas sob coordenação da Sustenere Publishing, da Companhia Brasileira de Produção Científica e seus parceiros autorizados. Os (as) autores (as) preservam os direitos autorais, mas não têm permissão para a publicação da contribuição em outro meio, impresso ou digital, em português ou em tradução. 